\title{
Construction of Theoretical Model for Sustainable Development in Future Mathematical Teachers of Higher Education
}

\author{
Natalia Pasichnyk ${ }^{1}$, Renat Rizhniak ${ }^{2}$, Inna Krasnoshchok ${ }^{3}$, Yuliia Botuzova ${ }^{2, *}, K^{*}$ ateryna Akbash ${ }^{1}$ \\ ${ }^{1}$ Department of Applied Mathematics, Statistics and Economics, Volodymyr Vynnychenko Central Ukrainian State Pedagogical \\ University, Ukraine \\ ${ }^{2}$ Department of Math, Volodymyr Vynnychenko Central Ukrainian State Pedagogical University, Ukraine \\ ${ }^{3}$ Department of Pedagogy and Management of Education, Volodymyr Vynnychenko Central Ukrainian State Pedagogical University, \\ Ukraine
}

Received March 3, 2020; Revised April 1, 2020; Accepted April 19, 2020

Copyright $\bigcirc 2020$ by authors, all rights reserved. Authors agree that this article remains permanently open access under the terms of the Creative Commons Attribution License 4.0 International License

\begin{abstract}
In this paper, the authors have identified the main features of constructing a theoretical model of the content part of the future mathematics teachers' training system in a pedagogical institution of higher education in Ukraine in the context of the implementation of the education model for sustainable development. In order to build such a model, the authors have organized a study in the form of an expert survey of specialists in the field of education, specialists in fundamental mathematical disciplines and in the methodic of teaching mathematics, master students, as well as mathematics teachers participants in retraining courses. The authors have determined the discipline (methodic of teaching mathematics) which became the basis for the model of the content of the future mathematics teachers' training system in the context of the implementation of the education model for sustainable development. The above course in the content such choice has been confirmed by the integration properties and capabilities of the discipline, the potential of its substantive and methodological components for the generalization and systematization of mathematical, pedagogical, natural-scientific and humanitarian knowledge and skills, as well as for the formation of systemic thinking. When studying the issue including a special course in the content part of teacher staff training program, aimed directly at creating an understanding of a human's role and one's dependence on nature, at creating a peaceful and open society, where everyone would have equal rights and opportunities, the authors have distinguished disagreements in experts' opinions.
\end{abstract}

Keywords Education for Sustainable Development, Mathematics Teacher, Model, Expert Evaluation, Content of Education

\section{Introduction}

The widespread recognition of education as the main factor in the transition to sustainable development has served a reason of education for sustainable development phenomenon emergence (hereinafter - ESD) at the turn of the millennia. The new civilization phenomenon has become a natural and logical development of the concept of sustainable development, proposed in 1987 by the International Commission on Environment and Development under the leadership of Gro Harlem Brundtland [21] and adopted at the 1992 UN Conference on Environment and Development in Rio de Janeiro [22] as a global development strategy. The decisions of this conference (as well as of the World Summit on Sustainable Development in 2002 in Johannesburg [23] became the basis and driving force of ESD and defined the main outlines of joint actions of the world countries aimed at developing and implementing a unified strategy for cooperation. In 2003, in Kyiv at the 5th conference "Environment for Europe", the Ministers of the Environment of 55 countries of the UN Economic Commission for Europe (ECE) region made a statement on the need to develop and implement a joint ESD strategy [24]. As a result, the main objectives of the UNECE Strategy for ESD in 2005 in Vilnius were identified [25]: a) providing political, regulatory and institutional assistance to ESD; b) promotion of sustainable development through all types of training and enlightenment; c) the acquisition by educators of the necessary knowledge and skills for 
ESD; d) ensuring the availability of training tools and manuals for ESD; e) promoting scientific research on ESD; f) strengthening cooperation on ESD at all levels within the UNECE region.

One of the key objectives of the UNECE Strategy for ESD is the development of knowledge by educators that enables them to integrate sustainable development into their subjects. In Ukraine, in various types of educational institutions, special disciplines and courses are introduced in the curriculum and plans, which provide introducing pupils and students with the problems of sustainable development. Such recommendations are embodied in the "National Strategy for the Development of Education in Ukraine for the period until 2021" [6]. An action plan for the formation and development of ESD also provides the priority provision of the qualified teachers' training. However, in practice there are only a few initiatives in the sphere of ESD. Despite the fact that the need to implement the principles of sustainable development in the education system, including pedagogical, is recognized at all levels, the overall progress in the field of teacher training for the implementation of ESD cannot be called significant.

Traditional views in education on the formation of students' knowledge, skills and abilities no longer satisfy society. Modern society needs not just bona fide executors who have certain knowledge, skills, but competent individual personalities. Indeed, in order to be competitive in the current dynamic conditions, young people need the ability to bring a personal context into the implementation of social and professional functions. After all, only a mature person can successfully solve the problems of the present. One of the modern educational problems is its rapid response to changes in society that requires an open education system, constant review and adaptation of the regulatory framework in education, ensuring the development and implementation of new training and upbringing methods and forms in the educational process, the formation of values and competencies necessary for sustainable development and self-realization of a person.

It is clear that new educational tasks will lead to a revision of the foundations of traditional learning. The tradition of teaching in pedagogical universities is connected with the norms of education. It is the achievement of educational standards that is the main goal of traditional education, designed to form a specific knowledge base for students, which is necessary for the formation of a specialist with certain personal qualities $[11,13]$. Therefore, traditional education is an important but insufficient aspect of training students for professional activities. Traditional training, given its "caution", closedness, conservatism, fulfills and "polishes" the educational process in the form of perfect structures, which provide the implementation of educational standards. The excellence of such educational structures is manifested in their persistence, orderliness, reasonability, predictability and ensures that the training system performs certain functions, namely, the achievement of educational standards. A student enclosed in such a training system acquires the properties of an operationalist, to a certain degree, an analyst and a conscientious executor. However, over time, the "perfection" of such a learning system turns into its opposite. Namely: it forms future teachers stereotypes of thinking, algorithms of actions (operations). The latter, in turn, lead to the traditional solution to the problem (stereotypes of actions), limit the formation of students' views of the world in its infinitely possible variety or as infinitely possible reality, do not allow the student to reveal new aspects of their own essential forces, develop their own intuitions (I want, I can, I'll solve, find, learn, grasp and the like), isolate one from life's reality.

Traditionally conservative learning provides activity, self-determination, self-realization and responsibility (the main characteristics of personality development) of a student within the framework of a training system created and perfect in a static understanding, which does not make it possible for a future specialist to realize the pulse of the society's real life. The semantic space, which is created for the student by a traditionally conservative learning system, forms only individual personality traits and does not provide adequate freedom for the development of the personality as a whole for one's self-determination and self-realization. One of the learning strategies is an attempt to reveal and use the essential forces of a person as much as possible, deeper, wider. Perfect in a static understanding, the training scheme is not allowed to fully reveal these forces and, therefore, limits the realization of personal potential. It is perhaps the main drawback of traditional education.

Implementing the model of education for sustainable development requires a change in approaches to its organization, namely, the introduction of innovative components. It should be noted that innovation is associated with upgrades, changes and modifications, the creation of the new, and innovative activity - with critical analysis, creativity, going beyond generally accepted standards, using new types and forms of activity, communication, and the exclusion of old types and forms, with readiness for the perception and reflection in the educational process of both new trends in the professional sphere, caused by the development of society, culture, science, and the changing needs and requirements of the future specialist. This or that innovation in teaching mathematical subjects at a pedagogical university should have innovative potential - the ability to provide a useful result from the innovation for a long time. Consequently, the innovativeness of training presupposes violation of the static perfection of the training system, the introduction of new activators into it, which causes a violation of persistence, predictability, and typical situations. Therefore, innovations are associated with a certain risk, unpredictability of learning outcomes, atypical situations, which complicate their implementation in the educational 
process.

Problem of Research. The main problem of our research is to construct a theoretical model of the content part of the future mathematics teachers' training system in the context of implementing an education model for sustainable development, taking into account the organization of such a learning system. This model will be built on innovative principles and will become a synergistic system in which violation of sustainability of the educational process aims at the emergence of its new dissipative (more open to innovations) structures.

Research Focus. The issue of the content of higher pedagogical education in various areas, taking into account the implementation of the education model for sustainable development, was analyzed in the pedagogical, social, humanitarian and philosophical works of scientists. Further, the most important works in the context of our research will be noted.

For the first time, a research aimed at summarizing the problems of teacher education for sustainable development was presented in an article by Pipere A., et al[14]. There was presented an analysis of scientific research in the field of teacher education to ensure sustainable development through the publication of the journal "Journal of Teacher Education for Sustainability" from 2005 to 2014. A significant part of the journal publications in recent years has been devoted to the definition and critical analysis of the content of training future teachers in the context of implementing an education model for sustainable development: organizing the training of English teachers in Bangladesh [3], interaction of theoretical knowledge and pedagogical practice in language teachers training in Iran [8] and natural science teachers in Saudi Arabia [1], features of school training of teachers in Jordan [2]. In the teaching guidance manual of O. Pometun [15], which was developed and published as part of the Education for Sustainable Development in Action project in partnership with Global Action Plan Int. organization, with the support of the Government of the Kingdom of Sweden, the competencies that a teacher must have in education for sustainable development are analyzed. In addition, the work presents programs of special courses "Lessons for Sustainable Development" for future teachers of chemistry, biology and geography, as well as for future primary school teachers in higher education and postgraduate education. The work of A. Kramarenko [10] proposes the author's concept of the formation of environmental values for future primary school teachers and the results of scientific searches in the context of education for sustainable development, as well as gives the main results of solving the problem and the corresponding results regarding its solution. Among the works on pedagogy in the context of our research, the monograph by T. Saienko, S. Boichenko[18], in which the authors, revealing the content of the modern innovative educational concept, conclude that the spread of environmental education, the activation of the informal education sector, the introduction of eco-management and eco-audit, the development of the psychological and pedagogical foundations of information and didactic support of the educational process will contribute to the formation of environmental thinking, consciousness, ethics, culture, that determines the factors of a sustainable society.

Carolyn Roberts and Jane Roberts[16] consider various aspects of sustainability in the framework of the bachelor and master students study program. Here a series of interdisciplinary courses has been compiled, which use a predominantly educational approach based on practical actions as means of developing literacy in sustainability issues among students. The authors explain each case study from a practical point of view, which makes it possible to transfer approaches and ideas to other disciplines. A report for The Higher Education Academy, "Sustainable Development in Higher Education: Current Practice and Future Developments", prepared by Gerald Dawe, Rolf Jucker and Stephen Martin [5], analyzes possible sections of the curriculum that should address sustainable development issues and methods of teaching these aspects. By performing such a research, The Higher Education Academy sought to identify best practices in approaches to teaching and curriculum development; learn if there are problems to include sustainable development in teaching and learning strategies; and assess the level of support needed to expand and deepen the process of introducing sustainable development ideas into higher education programs.

The socio-humanitarian aspect of the problem is revealed in V. Kutsenko [12], namely the essence and components of sustainable development. The author pays special attention to the social component of sustainable development, substantiates ways to improve the socio-humanitarian sphere. M. Hofman-Bergholm [7] performs a qualitative analysis of published studies in Finland, which analyze teacher education in the context of theoretical studies of perseverance and systemic thinking. The main conclusions of the article related to the importance for future teachers to understand the content of four dimensions - political, economic, social and environmental - sustainable development. The paper systematizes the analysis of existing obstacles to improving the quality of education and training for sustainable development, substantiates the need for teacher education programs to have an internal form of systemic thinking, the basis of which is created by critical thinking, negotiation and effective competencies [7]. An important conclusion of the article concerns the need for future teachers to develop skills and abilities that are consistent with the concept of sustainable development. This will allow them to develop a comprehensive understanding of the complexity of social systems and their interaction with nature (ibid.). The psychological and pedagogical aspects of the problem are analyzed in an article by A. Suleimenova, O. Ivanova [20], which presents the results of a research of the emotional competence and individual 
style of action of future teachers in the education system for sustainable development. Finally, issues of awareness and responsibility for sustainability decisions were analyzed by D. Andić, S. Tatalović Vorkapić [4], who presented the results of awareness of the consequences and distribution of responsibility for environmental / sustainability problems among students of four faculties of teacher education in four countries: Bosnia and Herzegovina, Croatia, Slovenia and Serbia. Based on the research results, the authors suggested that the country is the main factor determining awareness and responsibility for environmental / sustainability problems.

Among the philosophical works, we note the article by P. Saukh[19], in which the author proves that the algorithm for implementing the education strategy for sustainable development is the implementation of the ideas of the so-called "new humanism in education", which is characterized by the formation of holistic and non-linear thinking; movement from the school of knowledge to the school of understanding; a synergy of training and education based on amerological pedagogy; expansion and enrichment of the world outlook component of education.

\section{Materials and Methods}

\subsection{General Background of Research}

To build a theoretical model of the content part of the future mathematics teachers' training system, we have organized an expert survey. Experts were specialists in the field of education, in fundamental mathematical disciplines and in the methodic of teaching mathematics, master students at Volodymyr Vynnychenko Central Ukrainian State Pedagogical University (Kropyvnytskyi, Ukraine), as well as mathematics teachers - participants in retraining course in Vasyl Sukhomlynskyi Kirovohrad Regional Institute of Postgraduate Pedagogical Education (Kropyvnytskyi).

The main stages of the experimental study have been defined as follows: a) determination of the content of the expert survey (statements) of the participants in the experimental study; b) familiarization of the participants in the experimental study with the content part of the components of the expert survey (individual statements); c) performing an expert survey; d) processing the results of an expert survey; d) the conclusions of the performed expertise to build a theoretical model of the content part of the training system for future mathematics teachers.

\subsection{Instrument and Procedures}

In the course of the experimental research, the following methods have been used: theoretical - analysis of the psychological and pedagogical literature on the research problem; empirical - pedagogical observation of the educational and cognitive activities of students, conversations with scientific and pedagogical staff; mathematical methods of statistical processing of experimental data, with the help of which quantitative and qualitative relationships between research indicators have been determined.

To determine the significance of each statement, we have introduced the following indicators: indicator of generalized thought; an indicator of the degree of agreement of expert opinions; an indicator of the statistical significance of the indicator of expert opinions consistency; indicator of "activity" and competence of experts. The following indices have been used to determine the generalized indicator of the experts' thoughts: the arithmetic mean of a certain statement, the frequency of occurrence of the maximum possible points. To determine the indicator of consistency of expert opinions, the coefficients of variation of expert assessments for each of the statements and the coefficient of concordance (multiple correlation) of expert assessments have been calculated. To assess the statistical significance of the indicator of consistency of expert opinions, the Pearson criterion $\chi^{2}$ has been used. The activity indicator of experts has been determined by the completeness of their answers, and the competency indicator of the participants in the examination has been determined as the arithmetic mean of the index of degree of familiarization with the problem under consideration and the index of validity of expert answers (determined by the table of validity sources).

\section{Data Analysis and Results}

The main requirements for conducting experimental studies were to ensure the reliability, veracity and validity of experimental data. The experimental research has used a standardized methodology for conducting an expert survey, which ensured the reliability of experimental data. Reliability has also been ensured by the selection of highly qualified experts.

In the article, the authors intend to determine the content component of the future mathematics teachers' training system in Ukraine in the conditions of the functioning of the global model of educational activity - education for sustainable development.

Among 224 experts, 34 experts were specialists in fundamental mathematical disciplines and in the Methodic of Teaching Mathematics (6 Doctors of Sciences, 24 Doctors of Philosophy, 4 practitioners), 37 experts specialists in the field of education (representatives of methodological, pedagogical, psychological, philosophical and historical departments of the university; 15 Doctors of Sciences, 22 Doctors of Philosophy), 89 experts - master students of two courses of study specialties 014 Secondary Education (Mathematics) (Educational programs "Mathematics, Computer Science, Economics" and 
"Mathematics, Physics, Economics") and 64 experts teachers of mathematics from different schools of the Kirovohrad region. Processing of the results of the expert survey has been carried out according to the methodic "Assessing the relative importance of each individual statement." The received results of determining the relative importance of each individual statement have been evaluated on a 10-point scale ( 0 - false and dangerous statement, 1 - absolutely unimportant statement, 2 unimportant statement, 3 - rather unimportant statement, 4 - neutral unimportant statement, 5 - neutral important statement, 6 - rather an important statement, 7 - an important statement, 8 - an absolutely important statement, 9 - approval requires immediate implementation). The statements provided by the examination participants for analysis were as follows:

1. In the context of the implementation of education for sustainable development, the methodic of teaching mathematics in the process of training mathematics teachers is an educational discipline that integrates the contents of mathematical disciplines (algebra, geometry, mathematical analysis), disciplines of the psychological and pedagogical cycle (pedagogy, psychology), disciplines of the natural science cycle (physics, ecology) and disciplines of the social and humanitarian cycle (philosophy, history, economics, political science, sociology).

2. The methodic of teaching mathematics is a discipline that generalizes and systematizes mathematical, pedagogical, natural-scientific and humanitarian knowledge and skills, forms systemic thinking (a holistic thinking method that helps to understand the interconnected parts of a large system) and, as a result, ensures the acquisition of professional competencies in the context of the implementation of education model for sustainable development.

3. In classes on the methodology of teaching mathematics, future mathematics teachers form: a critical attitude to methods, means, and forms of learning; the ability to highlight the advantages and limitations of each method, means or form of training; awareness of the need for situational use of methods, means or forms of training in order to more fully implement didactic tasks. This will help students develop critical thinking in the context of recognizing the need for significant organizational and educational changes to promote sustainable development.

4. In the curriculum for training future mathematics teachers in the context of implementing the education model for sustainable development, a training course is planned that generalizes the understanding of the complexity of social systems and the features of their interaction with nature, reveals the features of the ecological economy, provides objective and scientific information on gender identity issues.
5. In the process of pedagogical training of future mathematics teachers in the context of the implementation of the education model for sustainable development, it is important to use information and communication technologies to solve educational problems of an integration nature and to form a systematic way of thinking. At the same time, students should critically evaluate what advantages this usage provides and what new problems are created by doing so.

6. The content and pedagogical training of future mathematics teachers in the context of the implementation of the education model for sustainable development is seriously influenced by relations and communication between teachers and students in order to clarify the existence of different approaches to solving problems, to determine different sets of values, ethics and morality.

7. The research work of future mathematics teachers in the form of the implementation of certain projects forms students' independence of the researcher, responsibility, activity, initiative, creativity, perseverance, criticality, systematic approach, the need for the search for new, and therefore, provides not only mathematical and pedagogical training of students, but also forms their personalities in the context of the implementation of the model of education for sustainable development.

8. Providing an individual curriculum at the final stage of future mathematics teachers' training in the context of implementing the education model for sustainable development is designed to optimize the time of students, adjust curricula in order to provide each student with the knowledge that one needs in the workplace, ensures the introduction of dual education elements in pedagogical higher education.

9. The formation and development of new didactic principles of education - systematic training, computerization of the educational process, fundamental training, the integration of knowledge, humanization and humanitarization of the educational process, the formation of the future specialist's personality. The filling of above principles with modern content is one of the priority directions for the development of pedagogical training of the future mathematics teachers in the context of the implementation of education for sustainable development.

Statistical processing of the determination by experts of different groups of the relative importance of each individual statement has yielded such results. Determining the degree of generalization of the experts' thought involved the calculation of the arithmetic average of a certain statement (table 1) and the frequency of occurrence of the maximum possible points (table 2). 
Table 1. The arithmetic average values of the assessment of claims 1-9 by different categories of experts

\begin{tabular}{|c|c|c|c|c|c|c|c|c|c|}
\hline Experts Category & St. 1 & St. 2 & St. 3 & St. 4 & St. 5 & St. 6 & St. 7 & St. 8 & St. 9 \\
\hline Mathematicians and Methodists & 8,088 & 8,147 & 8,029 & 5,882 & 7,941 & 7,706 & 8,088 & 7,971 & 7,912 \\
\hline Specialists in education & 7,973 & 8,000 & 8,000 & 7,297 & 7,378 & 7,703 & 8,054 & 7,919 & 7,730 \\
\hline Master students & 8,078 & 8,065 & 8,039 & 5,805 & 8,247 & 7,727 & 8,182 & 8,039 & 7,688 \\
\hline Teachers & 8,196 & 8,196 & 8,235 & 7,392 & 8,314 & 7,824 & 8,451 & 8,333 & 8,471 \\
\hline All experts & 8,107 & 8,112 & 8,094 & 6,496 & 8,058 & 7,746 & 8,219 & 8,071 & 7,924 \\
\hline
\end{tabular}

Table 2. Frequency of occurrence of the maximum possible points of assessment of claims 1-9 by different categories of experts (in percent)

\begin{tabular}{|c|c|c|c|c|c|c|c|c|c|}
\hline Experts Category & St. 1 & St. 2 & St. 3 & St. 4 & St. 5 & St. 6 & St. 7 & St. 8 & St. 9 \\
\hline Mathematicians and Methodists & 32,4 & 38,2 & 17,6 & 0,0 & 23,5 & 2,9 & 26,5 & 20,6 & 26,5 \\
\hline Specialists in education & 24,3 & 35,1 & 16,2 & 5,4 & 5,4 & 2,7 & 24,3 & 18,9 & 10,8 \\
\hline Master students & 38,2 & 40,4 & 20,2 & 0,0 & 39,3 & 3,4 & 33,7 & 27,0 & 13,5 \\
\hline Teachers & 39,1 & 43,8 & 26,6 & 4,7 & 28,1 & 4,7 & 39,1 & 29,7 & 43,8 \\
\hline All experts & 35,3 & 40,2 & 21,0 & 2,2 & 28,1 & 3,6 & 32,6 & 25,4 & 23,7 \\
\hline
\end{tabular}

As we see from Table 1, the arithmetic mean values of the assessment by various categories of experts of statements 1-9 indicate the general approval by the participants of the examination of the ideas proposed for analysis. Almost all statements were (on average) recognized by experts as important or absolutely important. Only when analyzing statement 4 the experts disagreed in opinions. The group of "mathematicians and methodologists" and the group of "master students" on average rated "planning a training course that summarizes the understanding of the complexity of social systems and the features of their interaction with nature" in the interval between "neutral important" and "rather important." The other two groups of experts leaned towards the interval between "important" and "absolutely important" when evaluating this statement. As a result, the variation in the average values of different categories of experts' estimates of statement 4 amounted to more than $13 \%$ (noting that the similar indicator of variation in the average values for other statements ranged from $0.7 \%$ for statement 6 to $5.4 \%$ for statement 5).

Table 2 shows that statements $1-3$ and 6-8 caused a relative unity of all categories of experts (the variation in the choice of the maximum possible points for evaluating these statements by different categories of experts is between $8 \%$ and $22.3 \%$ ). When analyzing statements 4,5 and 9 regarding the choice of the maximum possible points for their assessment, experts of different categories were not so unanimous (the corresponding indicators of variation were $103 \%, 49.6 \%$ and $55.2 \%$ ).

Nevertheless, in general, we can conclude that there is a certain degree of generalization of the thoughts of experts.

In order to determine the indicator of consistency of expert opinions, we have determined the coefficients of variation of expert assessments for each of the statements (table 3) and the coefficient of concordance $W$ of expert assessments (table 4). To evaluate the statistical significance of the $W_{\alpha}$ indicator of the consistency of expert opinions, the criterion $\chi^{2}$ has been used. 
Table 3. Coefficients of variation in the assessment by different categories of experts of each of the statements 1-9 (in percent)

\begin{tabular}{|c|c|c|c|c|c|c|c|c|c|}
\hline Experts Category & St. 1 & St. 2 & St. 3 & St. 4 & St. 5 & St. 6 & St. 7 & St. 8 & St. 9 \\
\hline Mathematicians and Methodists & 9,80 & 9,62 & 7,18 & 16,62 & 9,77 & 6,80 & 8,26 & 8,45 & 10,02 \\
\hline Specialists in education & 9,57 & 11,02 & 7,22 & 11,13 & 10,28 & 6,75 & 8,25 & 8,62 & 8,43 \\
\hline Master students & 10,15 & 10,81 & 6,93 & 16,33 & 8,17 & 6,55 & 7,60 & 8,43 & 9,80 \\
\hline Teachers & 10,40 & 10,92 & 6,80 & 10,78 & 7,17 & 6,63 & 6,45 & 7,15 & 7,89 \\
\hline All experts & 10,03 & 10,64 & 6,97 & 17,37 & 9,34 & 6,61 & 7,57 & 8,17 & 9,62 \\
\hline
\end{tabular}

We will clarify some aspects of the calculation of concordance. The initial score tables are calculated in the form of rank matrices $\left\{R_{j i}\right\}, j=\overline{1, m}, i=\overline{1, n}$ as the results of a survey of experts, where $n$ is the number of ranking objects and $m$ is the number of experts. Each of them ranks the variables according to the degree of their influence on the target attribute. In our tables, there are quite a few cases of indistinguishability of variables. Therefore, we have related ranks [17]. The calculation of the coefficient of concordance in a situation of the presence of related ranks is made by a more complex formula:

$$
\begin{gathered}
W=\frac{\sum_{i=1}^{n}\left\{\sum_{j=1}^{m} R_{j i}-\frac{m(n+1)}{2}\right\}^{2}}{\frac{1}{12} \cdot m^{2}\left(n^{3}-n\right)-m \sum_{j=1}^{m} T_{j}}, \\
\text { were } T_{j}=\frac{1}{12} \sum_{\gamma=1}^{l}\left(t_{\gamma}^{3}-t_{\gamma}\right),
\end{gathered}
$$

$\mathrm{Tj}$ - correction coefficient of $\mathrm{j}$ variable. It is calculated by all 1 «cases» of objects in distinguishability. Herewith $t_{\gamma} \quad$ - the number of indistinguishable objects of one "case".

For large $m$ and $n$, as in our case, statistically significant to test the hypothesis of a uniform distribution of ranks (agreement of rankings) there can be a very small value of $W$. It is known that $m \cdot(n-1) \cdot W$ (for $n>7$ ) has $\chi^{2}$ distribution with the number of degrees of latitude $f=n-1$. It follows that the critical value is $W_{\alpha}=\frac{\chi_{\alpha}^{2}}{m \cdot(n-1)}$. If $W>W_{\alpha}$, then with probability of $\alpha$ it can be concluded that the rankings are consistent [9].

Table 4. Concordance coefficients $W$ and estimates of statistical significance $W_{\alpha}$ of consistency indicators of expert opinions with confidence probability $\alpha=0,99$

\begin{tabular}{|c|c|c|}
\hline Experts Category & $W$ & $W_{\alpha}$ \\
\hline Mathematicians and Methodists & 0,851 & 0,074 \\
\hline Specialists in education & 0,195 & 0,068 \\
\hline Master students & 0,417 & 0,028 \\
\hline Teachers & 0,421 & 0,039 \\
\hline All experts & 0,273 & 0,012 \\
\hline
\end{tabular}

The data in Table 3 indicate the existence of acceptable variability in the experts' assessments of different categories of each of the statements. The data in Table 4 confirm the existence of a multiple relationship between expert estimates for all the proposed statements, since all values of $W$ exceed the corresponding critical values of

$\alpha$ Therefore, the opinions of experts on the proposed topic can be characterized as agreed.

For all statements, the maximum possible indicator of expert activity was noted (all experts rated all the statements). The competency indicator of the participants in the examination has been determined by us on the interval $(0 ; 1)$ as the arithmetic average of the coefficient of familiarization degree with the problem under consideration (determined by normalization - multiplying by 0.1 - each expert's own rating on a discrete scale from 0 to 10) and the expert argumentation index (determined personally by each expert on the table of sources of validity - table 5). The competency indicators of the examination participants are indicated in table 6.

Table 5. Distribution of the influence degree of argumentation sources by experts in the analysis of statements 1-9

\begin{tabular}{|c|c|c|c|}
\hline \multirow{2}{*}{ Source of validity } & \multicolumn{3}{|c|}{ Degree of source influence } \\
\cline { 2 - 4 } & high & middle & low \\
\hline $\begin{array}{c}\text { Performance of theoretical } \\
\text { analysis }\end{array}$ & 0,3 & 0,2 & 0,1 \\
\hline Use of production experience & 0,5 & 0,4 & 0,2 \\
\hline $\begin{array}{c}\text { Summarization of native } \\
\text { authors' works }\end{array}$ & 0,05 & 0,05 & 0 \\
\hline $\begin{array}{c}\text { Summarization of foreign } \\
\text { authors' works }\end{array}$ & 0,05 & 0,05 & 0 \\
\hline $\begin{array}{c}\text { Use of personal theoretical } \\
\text { and practical works }\end{array}$ & 0,05 & 0,05 & 0 \\
\hline Intuition & 0,05 & 0,05 & 0 \\
\hline
\end{tabular}

Table 6. Competence indicators of the expertise participants

\begin{tabular}{|c|c|}
\hline Experts Category & Expert Competency Index \\
\hline Mathematicians and Methodists & 0,887 \\
\hline Specialists in education & 0,845 \\
\hline Master students & 0,775 \\
\hline Teachers & 0,832 \\
\hline All experts & 0,820 \\
\hline
\end{tabular}

Considering the fact that the total competency indicators of the examination participants are close to 1 , we can 
conclude that all categories of experts participating in the survey are competent specialists in the field of the subject under discussion.

\section{Discussion}

Participants in the expert survey have confirmed one of the fundamental ideas of constructing the content part for future Ukrainian mathematics teachers' training in the context of the functioning of the global model of educational activity - education for sustainable development. This idea is that the discipline of the methodic of teaching mathematics is an educational discipline that integrates knowledge of various mathematical subjects, subjects of the cycle of psychological and pedagogical disciplines, philosophy and other sciences. It is in the process of studying the methods of teaching mathematics that the general didactic teaching principles (general methodology) are implemented, as well as special teaching methods for individual mathematical disciplines (special techniques). At the same time, the process of integrating knowledge of various disciplines is not just an eclectic sum of knowledge, but integrative knowledge, that is, interdisciplinary knowledge and related skills. Integrative knowledge is allowed to apply, for example, knowledge from the course of algebra in solving geometric problems; knowledge from the course of analytical geometry, algebra, mathematical analysis in solving equations and inequalities (especially increased complexity, which contain modules and parameters); knowledge of mathematical statistics, linear algebra and optimization in the study of development trends of economic, social, environmental, historical and other processes.

In addition, the methodology of teaching mathematics is designed to help students realize the role of various mathematical and humanitarian disciplines in the formation of knowledge and relevant thinking styles. Therefore, in classical mathematical analysis, one of the fundamental concepts is the concept of limit. It is the "dynamism" of the limit that forms the special style of thinking. Another style of thinking, which can arbitrarily be called "probabilistic," is formed by probability theory, when the world is considered not only as regular, but also random. However, accidents in probability theory correspond to a certain distribution - which may not occur in the real world. Geometry forms spatial representations of the world in the form of various geometry models of real space. Logic encourages conclusions based on certain rules, contributes to the formation of models of the real world. Original thinking styles are also characteristic of humanitarian disciplines. It is important to convey to students the understanding that any mathematical and any humanitarian discipline reflects the features of only certain aspects of the real world, abstracting from its diversity.
Consequently, one of the most difficult tasks in the methodology of teaching mathematics in pedagogical higher education is the formation of students' systemic thinking. Indeed, each mathematical and humanitarian discipline has certain concepts and relationships among them, has its own language, and thereby creates a specific semantic space of possibilities for displaying reality by the consciousness of the subject of instruction in the form of models of the corresponding discipline. Therefore, the methodology of mathematics should become a generalizing and systematizing discipline, which is designed to form the systemic thinking of future mathematics teachers and, as a result, to ensure the acquisition of professional competencies in the context of the implementation of the education model for sustainable development. This idea of building the substantive part of the future Ukrainian mathematics teachers' training in the context of implementing education for sustainable development was supported by all participants in the examination.

One of the forms of systemic thinking formation is the formation of critical thinking among students. It is in the classes on the methodology of teaching mathematics that students need to form a critical attitude towards methods, means, and forms of learning. At a minimum, this should be done so that they can highlight the advantages and limitations of each method, means or forms of training, recognize the need for situational application of them in order to more fully implement didactic tasks. Therefore, on the one hand, future mathematics teachers need to be given knowledge that reflects modern philosophical and methodological views on the problem of rationality in scientific knowledge, and thereby reveal the rationality of approaches, methods, tools and forms of teaching mathematics. On the other hand, it is critical to evaluate one or another rationality of the strategy of using approaches, methods, means and forms of training. Thus, the experts supported the idea of constructing a substantial part of the future mathematics teachers' training in Ukraine in order to promote the development of critical thinking among students in the context of recognizing the need for significant organizational educational changes to promote sustainable development.

It was not easy for the participants of the expertise to analyze the statement about the need to include the content part of future mathematics teachers' training course, the purpose of which is to generalize the understanding of the complexity of social systems and the features of their interaction with nature, to reveal the features of the ecological economy, to provide objective, impartial and scientific information on sexual orientation and gender identity. Noting that this was the only statement in which the opinions of experts were divided (although this division concerned the area of "importance" of this statement - from neutral to absolutely important), we consider this fact a problem, which indicates that among the specialists of the 
higher pedagogical education system (at least in the field of future mathematics teachers' training), there is an opinion that it is not necessary to include a course in the teacher training program that is aimed directly at creating an understanding of the role of human and one's depending on nature, on the creation of a peaceful and open society, where everyone would have equal rights and opportunities. Understanding the extreme nature of such our conclusion, we consider it necessary to separately (within the framework of another study) research the problem including the above course in the content of the mathematics teachers' training.

Experts of all categories noted the important role of information and computer technologies in the training of future mathematics teachers as those who help to implement the principles of didactics: scientific, accessibility, systematic, visual and fundamental. The study of various mathematical concepts, their interpretation, can be carried out in different mathematical subjects. An important role here can be played by the graphic capabilities of information and computer technologies. So, for example, when studying the concept of convergence of a functional series, its partial sums, residual term, rate of convergence, computer software products can be used. An important tool in information and computer technology can be in the formation of an understanding of certain theorems actions locality, for example, the existence and uniqueness theorems for solving a differential equation. Similarly, the capabilities of information and computer technologies are used in the analysis of pedagogical, environmental, economic, historical and other models. In this way, the integration of knowledge of various mathematical and humanitarian disciplines, knowledge of information technology, computer arises. It is important that the lessons on the methodic consider not just information and computer technologies, but their capabilities to provide solutions to various problems. Only such a critical analysis will allow one to learn how to correctly "select" the necessary information and computer technologies for realizing learning goals, thereby forming future mathematics teachers' skills to solve educational problems of an integration nature and, as a result, ensuring the formation of a systematic way of thinking.

The experts agreed greatly (in the interval between "important" and "absolutely important" closer to the latter) with the statement about the impact on the content of pedagogical training of future mathematics teachers in the context of the implementation of the education model for sustainable development of relationships and communication between teachers and students. Future teachers should understand that no teaching methods and means in themselves "teach" - teachers teach as individuals and, again, teach students' personalities. Therefore, when choosing methods and forms of learning a lot depends on what kind of relationship there is between the teacher and students. Whom do teachers see their students as? Objects of influence, active subjects of activity or people with equal rights in the universal understanding? Accordingly, it is advisable to plan and develop methods and forms of study. It is important that the teacher and students discuss classes themselves, which will create a dialogue between the teacher and students to find the best methods, means and forms of conducting classes.

The experts also agreed on the importance of organizing research work as a necessary factor in the formation of their personality in the context of the implementation of the education model for sustainable development in training future mathematics teachers. The research work of future mathematics teachers involves the application of knowledge, skills that are obtained in the study of various disciplines, to solve specific scientific problems. The organic combination of the study of mathematical and humanitarian courses with the scientific work of students is one of the important principles of professional training for future mathematics teachers. Scientific activity can have different aspects, which are displayed by the programs of scientific circles, problem groups. The scientific work of students in the form of the implementation of certain projects forms their independence as a researcher, responsibility, activity, initiative, creativity, perseverance, the search for the new, which allows revealing and realizing those facets of the personality that are not fully disclosed during traditional training in mathematical disciplines. An important place in the organization of scientific work of students is increasingly occupied by the project method, when a student independently develops a project of one's own activity and implements it. As a result, the scientific work of students expands their space of opportunities for professional training and for the development of their own personality, namely, contributes to the development of activity, self-realization and responsibility, which are the main criteria for personality development.

It was also confirmed by experts that an important factor in the professional training of teachers is the connection with real future activities. Therefore, future teachers of mathematics should have an idea of the organization features of pedagogical practice. However, not only teaching practice connects students with future professional activities. A significant part of future teachers gain professional and life experience directly in the workplace, while studying according to individual plans. It is individual learning plans that are designed to optimize the time of students, adjust curricula in order to provide the student with the knowledge that one needs in the workplace. In fact, through the implementation of individual student learning plans, it is possible to introduce elements of dual education in pedagogical higher education.

The experts paid special attention to the training of future mathematics teachers in terms of implementing education for sustainable development to such important 
concepts as technology, method, form, teaching tool, principle, and the formation of students' skills to explain the ambiguity of the definition of these concepts in the scientific literature and to indicate their perception by scientific community in a paradigmatic sense. Based on this, all categories of experts noted the importance of students understanding the new didactic principles of education that underlie in different teaching technologies, and the importance of adequately filling these principles with modern content. Only this way will enable future mathematics teachers to understand the features of the teaching technologies emergence that focus on the problem, individuality, differentiation, innovativeness, interactivity and, as a result, on the organization of the functioning of the global model of educational activity education for sustainable development.

\section{Conclusions}

Education is the most important and necessary condition for the implementation of the Sustainable Development Goals [26] in the world. Therefore, given the objective complexity of sustainability, quality teacher training plays a decisive role in the success of the organization of education to achieve the goals of sustainable development in the world and in each individual country. Ukraine adopted and adapted to plans for sustainable development, having formed a roadmap for action in all 17 areas (including education for sustainable development). It is clear that the action plan in the direction of education for sustainable development at the national level is characterized by sufficient commonality. Therefore, given the autonomy of higher education institutions in our country, each university that implements teacher's training implements its own vision of fulfilling a general plan of action.

The initial task of training mathematics teachers at Volodymyr Vynnychenko Central Ukrainian State Pedagogical University in the context of implementing the education model for sustainable development has determined the construction of a theoretical model of the content of the teaching system for future teachers. With this purpose, an examination has been conducted with four groups of experts (mathematicians and methodologists of mathematics, specialists in the field of education, teachers of mathematics, and master students). As a result of the expert survey, the organizers have come to such conclusions.

Firstly, a discipline is defined (Methodic of Teaching Mathematics), which will become the basis for the content model of the future mathematics teachers' training system in the context of the education model implementation for sustainable development. This choice is confirmed by the integration properties and capabilities of the discipline, the potential of its substantive and methodological components for the generalization and systematization of mathematical, pedagogical, natural-scientific and humanitarian knowledge and skills, as well as for the formation of systemic thinking.

Secondly, an important component of the content of the training system for future mathematics teachers will be information and communication technologies for solving educational problems of an integration nature and for the formation of systematic thinking.

Thirdly, the component of the content of the training system for future mathematics teachers in the context of implementing the education model for sustainable development will be their practical training in the form of organizing research projects and production projects in which the subject of research and production activities will be social systems and their interactions with nature.

Fourth, some experts did not support the inclusion of a special course in the content part of the teacher's training program, which is aimed directly at creating an understanding of the role of human and one's dependence on nature, at creating a peaceful and open society where everyone would have equal rights and opportunities. The reasons for such case may be different. The lack of motivation of the pedagogical society to introduce the substantial part of the named innovation into the educational process of teacher training could have effect. In addition, the reason could be the lack of centralized monitoring of the transformation of education for sustainable development by the Ministry of Education and Science of Ukraine. We also do not exclude insufficient training of the expertise participants themselves to understand the real goals and content of this discipline. Therefore, we consider it necessary to research separately (within the framework of another study) the problems including the above course in the content part of the mathematics teachers training.

\section{REFERENCES}

[1] Abdulwali H. Aldahmash, Saeed M. Alshmrani, \& Abdo N. Almufti (2017). Secondary School Science Teachers' Views about Their Reflective Practices. Journal of Teacher Education for Sustainability, 19 (1), 43-53.

[2] Alkhawaldeh, A. (2017). School-based Teacher Training in Jordan: Towards On-school Sustainable Professional Development. Journal of Teacher Education for Sustainability, 19 (2), 51-68.

[3] Amin, M.A., \& Greenwood, J. (2018). The UN Sustainable Development Goals and Teacher Development for Effective English Teaching in Bangladesh: A Gap that Needs Bridging. Journal of Teacher Education for Sustainability, 20 (2), 118-138.

[4] Andić, D., \& Tatalović Vorkapić, S. (2017). Teacher Education for Sustainability: The Awareness and 
Responsibility for Sustainability Problems. Journal of Teacher Education for Sustainability, 19 (2), 121-137.

[5] Dawe, G., Jucker, R., \& Martin S. (2005). Sustainable Development in Higher Education: Current Practice and Future Developments. A report for The Higher Education Academy.

[6] Decree (2013). About the National Strategy for Education Development in Ukraine for the period until 2021. Decree of the President of Ukraine from June 25, 2013 № 344/2013 https://zakon.rada.gov.ua/laws/show/344/2013

[7] Hofman-Bergholm, M. (2018). Changes in Thoughts and Actions as Requirements for a Sustainable Future: A Review of Recent Research on the Finnish Educational System and Sustainable Development. Journal of Teacher Education for Sustainability, 20 (2), 19-30.

[8] Khazaeenezhad, B., Tavakoli, M., \& Amirian Z. (2018). Making Sense of Core Qualities to Sustain Professional Development through Core Reflection Practice. Journal of Teacher Education for Sustainability, 20 (1), 93-105.

[9] Kobzar', A.I. (2006). Applied mathematical statistics. For engineers and scientists. Moskva: Fizmatlit. [in Russian]

[10] Kramarenko, A.N. (2014). Formation of future elementary school teachers' ecological values: issues and results of scientific searches in the conditions of education for sustainable developmen. Pedagogy of formation of creative personality in higher and secondary schools, 35(88), 220228. [in Ukrainian]

[11] Krasnoshchok, I. P. (2018). Individual educational trajectory of student: theoretical aspects. Pedagogy of formation of creative personality in higher and secondary schools, 60 . V.1. [in Ukrainian]

[12] Kutsenko, V. I. (2012). Strategy of sustainable development through the prism of socio-humanitarian sphere. Bulletin of the National Academy of Sciences of Ukraine, 1, 79-88. [in Ukrainian]

[13] Pasichnyk, N.O., \& Rizhniak, R.Ja. (2015). Educational indicators as the instrument of evaluating state and dynamics of educational systems development. Scientific Works of Kirovohrad National Technical University. Economics sciences, 27, 301-308. [in Ukrainian].

[14] Pipere, A., Veisson, M., \& SalÓte, I. (2015). Developing research in teacher education for sustainability: UN DESD via the Journal of Teacher Education for Sustainability. Journal of Teacher Education for Sustainability, 17(2), 543.

[15] Pometun, O. I. (2015). Training teachers for teaching sustainable development. Educational materials for lecturers of higher pedagogical educational establishments and systems of post-graduate pedagogical education: textbook. Eds. Pometun, O.I. [in Ukrainian].

[16] Roberts, C., \& Roberts, J. (2007). Greener by Degrees: Exploring Sustainability through Higher Education Curricula. University of Gloucestershire.

[17] Romashkina, G.F., \& Tatarova, G.G. (2005). Concordance coefficient in the analysis of sociological data. Sociology: methodology, methods, mathematical modeling, (4M), 20, 131-158. [in Russian].
[18] Saienko, T.V., \& Boichenko, S.V. (2013). Environmental education - the basis of sustainable society development: problems and prospects of higher education. Monograph. [in Ukrainian].

[19] Saukh, P.Yu. (2015). A new image of education in the context of sustainable society development idea: a transnational dimension. Education for sustainable development: an intercontinental dialogue of intellectuals, 146-161. [in Ukrainian].

[20] Suleimenova, A., \& Ivanova, O. (2018). Emotional Competence and Individual Style of Action of Future Teachers of Higher Education in the System of Education for Sustainable Development. Journal of Teacher Education for Sustainability, 20 (2), 44-63.

[21] United Nations (1987) Our Common Future. Report of the World Commission on Environment and Development. Brundtland Report. UN Documents: Gathering a Body of Global Agreements has been compiled by the NGO Committee on Education of the Conference of NGOs from United Nations web sites with the invaluable help of information \& communications technology https://www.ar e.admin.ch/dam/are/en/dokumente/nachhaltige_entwicklun g/dokumente/bericht/our_common_futurebrundtlandreport 1987.pdf.download.pdf/our_common_futurebrundtlandrep ort1987.pdf

[22] United Nations (1992) United Nations Conference on Environment and Development (Earth Summit), Rio de Janeiro from 3 to 14 June 1992. http://www.unesco.org/ed ucation/pdf/RIO_E.PDF

[23] United Nations (2002). Johannesburg Declaration on Sustainable Development. Johannesburg, South Africa, from 26 August to 4 September 2002. http://www.un-documents.net/jburgdec.htm

[24] United Nations (2003). Fifth Ministerial Conference «Environment for Europe». DECLARATION by the Environment Ministers of the region of the United Nations Economic Commission for Europe (UNECE) (Kiev, Ukraine, 21 - 23 May 2003). https://www.unece.org/filead $\mathrm{min} / \mathrm{DAM} / \mathrm{env} / \mathrm{efe} / \mathrm{Kiev} /$ proceedings/files.pdf/Item\%2014_ 15/14_15Documents/ece.cep.94.rev.1.e.pdf

[25] United Nations (2005). UNECE STRATEGY FOR EDUCATION FOR SUSTAINABLE DEVELOPMENT High-level meeting of Environment and Education Ministries (Vilnius, 17-18 March 2005) (Agenda items 5 and 6). http://www.unece.org/fileadmin/DAM/env/docume nts/2005/cep/ac.13/cep.ac.13.2005.3.rev.1.e.pdf

[26] United Nations (2015). Resolution adopted by the General Assembly on 25 September 2015. 70/1. Transforming our world: the 2030 Agenda for Sustainable Development. https://www.un.org/ga/search/view_doc.asp?symbol=A/R $\mathrm{ES} / 70 / 1 \&$ Lang $=\mathrm{E}$ 